\title{
COMBINED TESTS OF THE FISHER AND EXPECTATION HYPOTHESIS*
}

\author{
Raúl Garcia**
}

\section{Resumo}

(Testes Combinados das hipóteses de Fisher e Expectativas)

O papel das expectativas inflacionárias, para a Argentina durante o período de junho de 1977 a junho de 1982, na determinaçāo da taxa de juros nominal, é avaliada no contexto das Teorias de Fisher e Expectativas para estruturas de ternos da taxa de juros.

A Hipótese de Fisher é utilizada para obter uma decomposição da taxa de juros nominal de $n$ períodos em uma média das variações esperadas na taxa de inflação e da taxa de juro real ex-ante. Além disto, assume-se que os agentes econômicos formam expectativas racionais nas variáveis endógenas da economia. Para implementar esta última hipótese, é necessário aproximar a forma em que estas expectativas são formadas, implicando num conjunto de restrições não-lineares nos parâmetros do modelo utilizado.

As restrições não-lineares são verificadas utilizando o teste de Wald, que requer a estimação dos parâmetros do modelo irrestrito. Estas hipóteses não se rejeitam na maioria dos casos, mesmo quando ambas as hipóteses são testadas simultaneamente ou separadamente.

\begin{abstract}
The role played by in inflationary expectations in the deternination of nominal rates of interest is evaluated within the framework of the Fischer and Expectation Theory of the term structure of interest rates for Argentina during the period June 1977 - June 1982.

The Fisher Hypotesis is utilized to provide a decomposition of a $n$-period nominal interest rate into the average of expected changes in the inflation rate an of the ex-ante real rate of interest. Furthermore, economic agents are assumed to form rational expectations on the exogenous variables of the economy. This latter assumption together with the Fisher and Expectations Hypotesis imply a set of nonlinear restrictions among the parameters of the model utilized to approximate the way in which those expectations are formed.

The nonlinear restrictions are evaluated by means of the Wald test wich only requires estimation of the unrestricted model. The tests conducted do not reject, in almost all cases, the hypothesis, whether both hypothesis are simultaneously or separately held.
\end{abstract}

*This paper draws on material contained in my $\mathrm{PhD}$ dissertation at the University of Washington. I appreciate comments received by Hugo Balacco, Pedro Valls Pereira and anonymous referee. Of course, all errors remain my own responsability.

**IEERAL de Fundación Mediterránea, Universidad Nacional Cordoba

R. de Econometria Rio de Janeiro v. IX, n¹, p.7-29 abril 1989




\section{Introduction.}

This paper presents theoretical and empirical research on the term structure of interest rates in the short run for Argentina from June 1977 to June 1982, a period in which these were market determined. The role that inflationary expectations play in the determination of nominal rates of interest on financial assets (time deposits) of different maturities is assessed within the well known Fisher Hypothesis (FH) and Expectations Theory (EH) of the Term Structure. The Expectations Theory asserts that the nominal rate on an $n$-period bond with no coupon payment can be decomposed, as an approximation, into the average of expected one-period nominal rates of interest over the span of life of the instrument.

Utilizing the Fisher Hypothesis allows a decomposition of the n-period rate into the average of expected changes in the inflation rate and ex-ante real rates. The expectations that market participants form about future nominal rates and infiation rates are said to be rational in the sense that given a structural model for the economy with a specified stochastic structure, economic agents anticipated values of those variables correspond to the conditional value obtained from the model.

The Expectations and Fisher Hypothesis together with the assumption of rationality of expectations imply a set of nonlinear restrictions among the parameters of the multivariate forecasting system utilized to approximate the market expectations. It is shown that the Expectation and Fisher Hypothesis can be independently evaluated within the same forecasting model and combined in a simple manner to yield a restriction on changes in the long rate expressed as the average of expected changes in the inflation rate.

Evaluation of the set of nonlinear constraints implied by the above hypothesis is one of the main objectives in this paper. The forecasting model with no restrictions is called the "unrestricted model" or model under the alternative hypothesis, and when the nonlinear constraints are incorporated and assumed to be valid, it is called the model under the null hypothesis or "restricted model". The simpler approach does not require estimation of the restricted model and the constraints are evaluated by means of the Wald statistic using the estimates from the unrestricted model. 
The paper has been estructured in the following way: section 2 presents the Expectation and Fisher Hypothesis. Section 3 delineates the set of restrictions implied by the $\mathrm{EH}$ and $\mathrm{FH}$ and the test procedures. Section 4 details the results of estimation and testing the multivariate models and conclusions. The test statistics employed favored the acceptance of the $\mathrm{EH}$ and F H hypothesis at conventional significance levels. In particular, the representation of the change in long rates as the simple average of the changes in expected inflation rates seemed appropriate in spite of the stronger assumption utilized: namely, the Fisher Hypothesis. Moreover, when other variables such as alternative definitions of the money stock were utilized in the multivariate system the main conclusions were not changed. Thus, for this particular sample and model it was not possible to reject these hypothesis categorically. Other models or alternative stochastic representations could, of course, yield different results and this would seem a fruitful avenue of further research.

\section{The Expectations and Fisher Hypothesis.}

\subsection{The Expectations Hypothesis of the term structure of interest rates.}

The pure version of the expectations hypothesis ( $\mathrm{EH})$, states that holding to an $n$-period bond may be regarded as identical to holding to $n$ consecutive one-period bonds. Support for the hypothesis is based on the presence of market participants who are willing to arbitrage profitable opportunities and thus bring into equality the forward rates implicit in long term bonds with the short term rates expected to prevail in future periods. The relationship among long term rates, short term rates and forward rates can be approximated with the following well-known formula:

$$
R_{n, t} \equiv(1 / n) *\left(R_{1, t}+{ }_{t} F_{t+1}+\cdots+{ }_{t} F_{t+n-1}\right)
$$

where $R_{n, t}$ denotes the long term rate corresponding to an $n$ period bond that carries payments, $R_{1, t}$ is the one period (short term) rate and ${ }_{t} F_{t+j}$ is the forward rate at time $t$ for period $t+j$.

The definitional equation (1) yields testable implications when it is hypothesis, as in the expectations hypothesis, that the 
forward rates represent the expected short term rates in subsequent periods. To implement empirically the theory, and to characterize further the expectations that market participants hold, the Rational Expectations hypothesis (REH) will be imposed.

This hypothesis states that, in forming expectations of the endongenous variables, market participants will take into account the form in which variables are related according to economic theory (Muth (1961)). Thus, according to the REH,

$$
{ }_{t} F_{t+j}={ }_{t} R_{1, t+j}
$$

where,

$$
{ }_{t} R_{1, t+j} \equiv E\left[R_{1, t}+j \mid I_{t}\right.
$$

$\mathrm{E}[$.$] is the expectations operator and I_{t}$ is the information set available at time $t$ to all market participants, including the past history of short term rates and long term rates. Therefore, in the determination of the forward rate at time $t$, the expected value of the short-term rate is being assessed with information available at that moment. ${ }^{1}$

\subsection{The Fisher Hypothesis.}

The Fisher Hypothesis states that the nominal rate of interest can be decomposed, as an approximation, as the sum of the equilibrium real rate of interest and the expected inflation rate. Distinguishing real from nominal interest rates is important in the context of a monetary economy, as the following paragraph from Irving Fisher illustrates:

If the monetary standard were always stable with reference to goods, the rate of interest, reckoned in terms of money, would be the same as if reckoned in terms of goods. When, however, money and goods change with reference to each other-in other words,

\footnotetext{
${ }^{1}$ When allowing for liquidity premiums, forward rates will not be unbiased predictors of future short term rates, since,

$$
{ }_{t} F_{t+\jmath}={ }_{t} R_{t+j}+{ }_{t} L_{t+j}
$$

where ${ }_{t} L_{t+\jmath}$ represents the liquidity premium. Since liquidity premiums may be variable over time, testing of alternative theories of the term structure will become more complex as they will be composite in nature. See Richard Roll (1970, Chapter IV).
} 
when the money standard appreciates or depreciates in value in terms of goods-the numbers expressing the rates of interest, one reckoned in terms of money and the other in terms of goods, will be quite different. Moreover, the former, or money rate, the only rate quoted in the market, will be influenced by the appreciation or depreciation.

In algebraic notation,

$$
R_{1, t}=r_{t}^{e}+P_{t}^{e}
$$

where $r_{t}^{e}$ is the equilibrium real rate at time $t$ and $P_{t}^{e}$ is the expected inflation rate between $t$ and $t+1$. To add empirical content to the theory, the following two maintained hypothesis have been usually introduced: (i) that expectations of inflation are rational, and (ii) that the ex-ante real rate is constant,

(i) $P_{t}^{e}=E\left[P_{t+1} \mid I_{t}\right] \equiv_{t} P_{t+1}$

(ii) $r_{t}^{e}=r \forall t$.

The assumption of constancy of the real rate, although convenient, is by no means the most realistic assumption and has raised a great deal of controversy. ${ }^{2}$

\section{The Expectations and Fisher Hypothesis as restric-} tions on the forecasting model.

As shown above, long rates can be expressed identicaily as an arithmetic average of the short rate and forward rates. To transform the identity into a testable hypothesis it was asserted that forward rates represented the expected future short rates assessed by market participants at time $t$. Furthermore, according to the Fisher hypothesis, short rates can be decomposed as the sum of an expected real rate plus an assesment of the one period inflation rate, consequently, forward rates would be unbiased predictors of short rates in the absence of liquidity premiums, but biased predictors of the expected inflation rate given the presence of the real rate.

\footnotetext{
${ }^{2}$ See Mundell (1969) for a macroeconomic analysis of the effects of a change in the expected inflation rate on real rate; Kochin (1980), Hartman and Makin (1982) for the effects steemming from uncertainty about the price level and Nelson an Schwert (1977) critician of Fama's (1975) assumption of constancy of the real rate.
} 
The apparent non-stationarity behavior of the nominal rate of the various maturities on time deposits might result from nonstationary behavior of the real rate. Among other possible nonstationary representations, it will be argued here that the expected real rate of interest displays a random walk behavior.

Since $R_{1, t}=r_{t}^{e}+{ }_{t} P_{t+1}$, where $r_{t}^{c}$ : expected real rate, ${ }_{t} P_{t+1}$ : expected inflation rate and $r_{t}^{e}=r_{t-1}^{e}+v_{t}$ with $E\left(v_{t}\right)=0$ and $E\left(v_{t} v_{s}\right)=\sigma^{2}$, for $t=s$ and 0 otherwise, and $E\left(v_{t} \mid I_{t-1}\right)=0$, then, forecasts of the expected real rate are ${ }_{t} r_{t+j}^{e}=r_{t}^{e}$ for any $j \geq 0$. The short rate at any $j^{t h}$ period is, $R_{1, t+j}=r_{t+j}^{e} t_{t+j} P_{t+j+1}$ and the marketś expected value at time $t$ is, ${ }_{t} R_{1, t+j}=r_{t}^{e}+{ }_{t} P_{t+j+1}$ since ${ }_{t} F_{t+j}={ }_{t} R_{1, t+j}$, and replacing in the identity for the long rate, $R_{n, t}(1)$, then,

$$
R_{n, t}=(1 / n) *\left({ }_{t} P_{t+1}+\cdots+{ }_{t} P_{t+n}\right)+r_{t}^{e}
$$

First differencing the above expression,

$$
D R_{n, t}=(1 / n) *\left(D_{t} P_{t+1}+\cdots+D_{t} P_{t+n}\right)+v_{t}
$$

where $D$ is the first difference operator, and $v_{t}$ is stationary by assumption; this does provide for a rationalization of a disturbance term in the equation for the long rate in the forecasting system to be presented later. Furthermore, taking conditional expectations on both sides of the above expression on a subset of $I_{t}$, namely $I_{t-1}$ containing past information available to the econometrician in the form of past short rates, long interest rates and inflation rates, then,

$$
E\left[D R_{n, t} \mid I_{t-1}\right] \equiv_{t-1} D R_{n, t}=(1 / n) *\left(t_{-1} D P_{t+1}+\cdots+t_{t-1} D P_{t+n}\right)
$$

since $t_{-1} v_{t}=0$ by assumption. That is, the expected changes of the long rate conditional on $I_{t-1}$ can be equally explained by the simple average of the forecasts of the inflation rate conditional on that same information set.

If the market, or true, expectations were obtained from a linear structural model on the information set $I_{t}$, the expectation would also be linear on that information set, though nonlinear in the parameters of the structural system, since these expectations are derived from the reduced form of the model. 
Utilizing optimal linear forecasts to proxy for those expectations, a linear regression on the left hand side of the equation (6) is obtained; i.e., $t_{-1} D R_{n, t}$

$x_{i t-1}$ is one element of the information set $I_{t-1}$ and the vector of coefficients $b=\left(b_{1}, b_{2}, \cdots\right)$ must obey the behavior of the forecasting coefficients on the right hand side of the equation; i.e., $x_{t}^{\prime} b=x_{t}^{\prime} B$, where $B$ is a vector whose elements are nonlinear in the coefficients of the forecasting model used to obtain ${ }_{t-1} D P_{t+j}, j=1, \cdots, n$.

Note also that following a similar line of reasoning, $t-1 D R_{1, t}$ ${ }_{t-1} D P_{t+1}$. Expected changes in the nominal rate of interest are in a one-to-one relationship with expected changes in the one-periodahead inflation rate conditional on the same information set. This relationship is the Fisher Hypothesis in first differences. It is basic relationship that allows the decomposition of the change in long-rate as the average of expected changes in the inflation rate.

Next, using, the approach presented in Sargent (1979) it will be shown that the nonlinear relationship among the parameters of the forecasting model implied by the expectations hypothesis, formulated in terms of the average of the expected changes in the short rates, can he expressed as:

$$
{ }_{t-1} D R_{n, t}
$$

or in terms of averages of expected changes in the inflation rate:

$$
{ }_{t-1} D R_{n, t}
$$

with the Fisher Hypothesis connecting both in the form

$$
{ }_{t-1} D R_{1, t}={ }_{t-1} D P_{t+1}
$$

To facilitate the testing of the restrictions a trivariate vector autoregression in first differences is presented for the short rate, long rate and inflation rate.

Consider the following multivariate system of equations,

$$
\begin{aligned}
D R_{1, t} & =\sum_{i=1}^{m} \alpha_{i} D R_{1, t-j} \\
& =\sum_{i=1}^{m} \mu_{i} D R_{1, t-i}+\sum_{\substack{i=1 \\
m}}^{m} D P_{t-i}+\sum_{\substack{i=1 \\
m}}^{m} \theta_{i} D R_{n, t-i}+u_{2, t} D R_{n, t} \\
& =\sum_{i=1}^{m} n_{i} D R_{1, t-i} \prod_{i=1}^{m}
\end{aligned}
$$


where the vector of disturbances $u_{t}=\left(u_{1, t}, u_{2, t}, u_{3, t}\right)^{\prime}$ has first and second moments of the form, $E\left(u_{t}\right)=0, E\left(u_{t} u_{s}^{\prime}\right)=\sum$ for $t=s$ and 0 otherwise.

Utilizing the state-space representation, system (10) can be cast as a first-order multivariate equation in first differences,

$$
\begin{aligned}
& D R_{t}=A * D R_{t-1}+U_{t} \\
& D R_{t}=\left(D R_{1, t} \cdots D R_{1, t-m}, D P_{t} \cdots D P_{t-m}, D R_{n, t} \cdots D R_{n, t-m}\right)^{\prime} \\
& U_{t}=\left(u_{1, t} 0 \cdots 0, u_{2, t} 0 \cdots 0, u_{3, t} 0 \cdots 0\right)^{\prime}
\end{aligned}
$$

where $m$ is the number of lags and

$$
A=\left[\begin{array}{cccccccccccc}
\alpha_{1} & \ldots & \alpha_{m-1} & \alpha_{m} & \pi_{1} & \ldots & \pi_{m-1} & \pi_{m} & \beta_{1} & \ldots & \beta_{m}-1 & \beta_{m} \\
1 & \ldots & 0 & 0 & 0 & \ldots & 0 & 0 & 0 & \ldots & 0 & 0 \\
\vdots & \vdots & \vdots & \vdots & \vdots & & \vdots & \vdots & \vdots & & \vdots & \vdots \\
0 & \ldots & 1 & 0 & 0 & \ldots & 0 & 0 & 0 & \ldots & 0 & 0 \\
\mu_{1} & \ldots & \mu_{m-1} & \mu_{m} & \theta_{1} & \ldots & \theta_{m-1} & \theta_{m} & \theta_{1} & \ldots & \theta_{m-1} & \theta_{m} \\
0 & \ldots & 0 & 0 & 1 & \ldots & 0 & 0 & 0 & \ldots & 0 & 0 \\
\vdots & \vdots & \vdots & \vdots & \vdots & & \vdots & \vdots & \vdots & & \vdots & \vdots \\
0 & \ldots & 0 & 0 & 0 & \ldots & 1 & 0 & 0 & \ldots & 0 & 0 \\
\mu_{1} & \ldots & \eta_{m-1} & \eta_{m} & \omega_{1} & \ldots & \omega_{m-1} & \omega_{m} & \delta_{1} & \ldots & \delta_{m-1} & \delta_{m} \\
0 & \ldots & 0 & 0 & 0 & \ldots & 0 & 0 & 1 & \ldots & 0 & 0 \\
\vdots & \vdots & \vdots & \vdots & \vdots & & \vdots & \vdots & \vdots & & \vdots & \vdots \\
0 & \ldots & 0 & 0 & 0 & \ldots & 0 & 0 & 0 & \ldots & 1 & 0
\end{array}\right]
$$

Define also the following unit vectors $e$,

$$
\begin{aligned}
& e_{1}=(1 \cdots 00 \cdots 00 \cdots 0) \\
& e_{2}=(0 \cdots 01 \cdots 00 \cdots 0) \\
& e_{3}=(0 \cdots 00 \cdots 01 \cdots 0)
\end{aligned}
$$

Forecasts of the vector $D R_{t}$ for any $j^{t / h}$ period, conditional on the information subset which includes lagged values of $D R_{1, t}, D R_{n, t}$ and $D P_{t}$, is,

$$
{ }_{t-1} D R_{t+j}=A^{j+1} * D R_{t-1}, \quad j \geq 0 .
$$

Premultiplying by any of the unit vectors $e$ will yield a forecast of the variable of interest. For instance, premultiplying expression (12) by $e_{1}$ on both sides yields the expected short rate 
at $t-1$ for period $t+j$ which depends on all variables of the forecasting model dated $t-1$.

$$
{ }_{t-1} D R_{1, t+j} \equiv e_{1} *_{t-1} D R_{t+j}=e_{1} * A^{j+1} * D R_{t-1}
$$

The restriction implied by the $\mathrm{EH}$ as an average of future short rates is obtained by replacing the forecasts (13) in expression (7) and then equating to the systematic part of ${ }_{t-1} D R_{n, t} ; e_{3} * A *$ $D R_{t-1}$, which yieids,

$$
e_{3} * A * D R_{t-1}=(1 / n) *\left(e_{1} * A+\cdots+e_{1} * A^{n}\right) * D R_{t-1}
$$

When the long-rate is expressed as an average of the changes in the expected inflation rate, the restriction in terms of parameters of the model can be obtained in a similar fashion by premultiplying the vector of forecasts by the unit vector $e_{2}$ and equating to the systematic part of $D R_{n t}$ which gives the expression

$$
e_{3} * A * D R_{t-1}=(1 / n) *\left[e_{2} * A^{2}+\cdots+e_{2} * A^{n+1}\right] * D R_{t-1}
$$

Notice that the Fisher Hypothesis implies a restriction of the form,

$$
e_{1} * A * D R_{t-1}=e_{2} * A^{2} * D R_{t-1}
$$

following a similar procedure. Furthermore, the restriction in $\left(8^{\prime}\right)$ can be derived directly from $e_{1} * A^{2}=\left(e_{1} * A\right) * A$ if the restriction in $\left(9^{\prime}\right)$ is inserted in $\left(7^{\prime}\right)$.

\subsection{Econometric implementation of the theory.}

The choice of an appropriate forecasting model involves several steps, the first being the selection of variables whose relationship is useful in the sense of providing the most accurate predictions of the relevant variable. Theoretically, the most advisable procedure would involve the specification of a structural model and them testing the restrictions within its framework. From the practical point of view, such estimation could be extremely complicated. Thus, an unrestricted multivariate autoregressive model was estimated employing those variables expected to carry useful information in the short run and which are publicly available to market participants forming their expectations at time $t$ : 
namely interest rates of the various maturities, the inflation rate and money growth rates. ${ }^{3}$

\subsection{Tests of the restrictions.}

The choice of the appropriate test (likelihood ratio-LR-, the Lagrange multiplier test-LM- and the Wald test -W-) depends on its relative advantage with regard to the necessary computational work in estimating the models under the null or the alternative hypothesis.

Computation of the $L R$ requires that the system be estimated under both hypothesis, while implementation of the Wald test requires estimation under the alternative hypothesis. ${ }^{4}$

Restrictions arising from the $\mathrm{EH}$ and $\mathrm{FH}$ involve nonlinear estimation of the resultant model. Thus it appears that if one is not interested in obtaining the restricted estimates, per se, a more convenient approach is to use the Wald test which requires estimation only under the alternative (linear) hypothesis.

This is the methodology taken in this paper.

Let's denote by $g_{1}(\Omega)=e_{3} * A-(1 / n) e_{1} *\left(A+\cdots+A^{n}\right)=0$ and by $g_{2}(\Omega)=e_{1} * A-e_{2} * A^{2}=0$, the restrictions in implicit form, corresponding to the $\mathrm{EH}$ and the $\mathrm{FH}$ respectively, and by $g_{3}(\Omega)=e_{3} * A-(1 / n) * e_{1} *\left(A^{2}+\cdots+A^{n+1}\right)$ that resulting from combining the $\mathrm{EH}$ and the $\mathrm{FH}$.

Assuming the vector of OLS coefficients is asymptotically normally distributed, the Wald statistic will have a $\chi^{2}$ limiting distribution. Its mathematical expression is,

$$
W_{i}=g_{i}(\widehat{\Omega}) *\left[D_{i}^{\prime}\left(\widehat{\Sigma} \times\left(x^{\prime} x\right)^{-1}\right) D_{i}\right]^{-1} g_{i}(\widehat{\Omega})^{\prime} \sim \chi^{2}(q) i=1,2,3
$$

where $q$ denotes the number of restrictions, $(\cdot)$ indicates, $\Sigma$ is define the product-moment matrix of the regressors used in estimating system (10).

$$
\widehat{\Omega}=(\hat{\alpha}, \hat{\theta}, \cdots), D_{i}=\left.\left(\partial g_{i} / \partial \Omega\right)\right|_{\Omega}=\widehat{\Omega}
$$

\footnotetext{
${ }^{3}$ In an upcoming paper, I will show the results obtained by estimating the model when restrictions are incorporated. This model relies on linearizing the constraint.

4See Engle (1982) for a general treatment of the subject and the wide variety of cases to which these tests can be applied and Hoffman Schmidt (1981) and Hoffman and Schlagenhauff (1983) for applications to the literature of Rational Expectations.
} 
April 7, $1990 \Omega$ is the vector of parameters from the autoregressive model, and $D_{i}$ is the matrix of first derivatives of the constraint with respect to all the parameters in A valued at $\Omega=\widehat{\Omega}^{5}{ }^{5}$

\section{Empirical results.}

\subsection{Estimation of the autoregressive models.}

Using monthly data for the period June 1977-June 1982, this section presents estimation results for the multivariate systems of the form $\left(x_{t}, y_{t}, z_{t}\right)$ as well as tests of the restrictions (7-9).

The variables used in the estimation of the forecasting system are: $R_{1, t}, R_{3, t}$ and $R_{6, t}$ which are respectively the nominal monthly rates on unregulated time certificate deposits, etc. 30, 90 and 180 days at financial institutions. Source: BCRA. $P_{t}$ is the wholesale price index. Source: INDEC.

$M_{1}$ is measured as currency plus demand deposits, and $M_{2}$ includes savings and time deposits. Source: BCRA.

Because market determined interest rates on time certificate deposits are available only for a short time span for all the maturities (30,90 and 180 days) considered in this paper, it has been difficult to determine an appropriate degree of differencing to correct for non-stationarity. Two aspects are of concern in this matter. First, when the sample size is not large, the autocorrelation function decays too rapidly to be in agreement with that of a non-stationary process. Second, the differencing of the series a dissimilar number of times tends to distort the relationship between them. Statistical tests performed on the interest rate equation have produced evidence which suggests first differencing of the interest rate series. ${ }^{6}$ Consequently, I will present the set of

\footnotetext{
${ }^{5}$ Calculation of the derivatives could be performed numerically or analytically. I have adapted a procedure utilized by Baillie (1983) for testing market efficiency in the foreign exchange market that allows the computation of analytical derivatives. The Appendix shows how $D_{i}$ can be calculated using a simple recursive procedure.

${ }^{6}$ One approach is to examine the eigenvalues of the systems. The largest of the eigenvalues should be stationary. When an $A R(2)$ representation was estimated in levels, the largest of the moduli was generally close to one, indicating the non-stationarity of the system. In a second approach, univariate AR(1) representations for the nominal rates of interest $R_{1 t}, R_{3 t}$ and $R_{6 t}$ were fitted in levels and with a constant term included; i.e., models of the form $X_{t}=a_{0}+a_{1} X_{t-1}+a_{2}\left(X_{t-1}-X_{t-2}\right)+V_{t} \cdot V_{t}$ white noise. To test for
} 
results in first differences, which are indeed stationary and are to be interpreted as acceleration rates.

When estimation of the unrestricted system was performed an $\mathrm{AR}(1)$ representation for the systems $\left(D R_{1 t}, D P_{t}, D R_{3, t}\right)$ $\left(D R_{1 t}, D P_{t}, D R_{6, t}\right)$ likelihood ratio tests.

Estimates for the above systems are shown in Table 1. The standard errors of the coefficients for each of the equations show that the regressors have low explanatory power in general, though the diagonal coefficients seem to be more significant. The diagonality feature would indicate that each of the series could be explained by its own past alone. ${ }^{\text {? }}$

To evaluate the system as a whole, a Wald test was computed corresponding to the null hypothesis that all coefficients in the system were insignificantly different from zero; for both systems the hypothesis was rejected at a one percent significance level.

Stationarity requires that the eigenvalues of the state-space matrix be less than one in modulus, and this seemed to be the case for both systems. Constant terms were statistically insignificant which, combined with the stationarity feature of the system, would indicate that the expected value of the acceleration rates is zero. Interestingly, the equation for the inflation rate suggests that accelerations in the inflation rate reverse themselves (though not completely) since a one percent change in the inflation rate in period $t-1$ is followed by a reduction of almost half a point in the subsequent period, ignoring changes stemming from other variables in the system.

Other statistics in the tables are used to indicate for possible

the existence of a unit root, that is, $a_{1}=1.0$ a method delineated in Fuller (1976), pp. 366-82, was employed. Estimates of $a_{1}$, the standard error (sa $)$ and the statistic $C_{u}=a_{1}-1 / s a_{1}$ are shown below.

The author also shows the empirical cumulative distribution of the statistic for alternative sample sizes; i.e., $P\left(C_{u}^{*} / a_{1}=1\right)$. The values of $C_{u}^{*}$ for $n=50$ are respectively $-3.58,-2.93,-2.60$ for $0.01,0.05$ and 0.10 significance levels in all cases. Comparison of these critical values with the actual values of the statistics obtained from our sample $(n=60)$ would indicate that the null hypothesis of a unit root would be accepted at a 0.05 significance levels in all cases.

${ }^{7}$ The insignificant coefficients for the lagged values of the changes in the short and long interest rates are most likely due to the presence of multicollinearity, since the correlation coefficient for both variables is in the order of 0.93 . 
misspecification in the model. First, no important seasonality effects appear to stem from the price series for this particular sample period, since the correlation coefficient at the 12th lag $(r(12))$ is statistically insignificant in all cases. Second, the overall Portmanteau statistic indicates that the null hypothesis of a white noise residual for each of the equations is accepted at conventional significance levels. ${ }^{8}$

Tables 2 and 3 show estimation results for the systems $\left(D R_{1, t}, D P_{t}, D M_{i, t}\right), i=1,2$, which combine monetary and inflationary effects and neglect long-term rates as explanatory variables in the system. These systems can be viewed as special cases of a set containing lagged long rates and upon which a causality structure stemming from short rates, inflation rates and money growth rates to long rates has been imposed on a system which includes the latter.

Since our concern is to determine which definition of the money stock is more adequate for forecasting purposes, a choice must be made according to some prespecified criteria. The AIC criteria provide an acceptable approach, and for these particular systems the AIC is minimized for the M2 definition of the money stock.

Inclusion of monetary aggregates does not appear to affect the significance of the stochastic system. Comparison of the standard errors of the regression for each of the equations (other than differences in the money growth rates) in Table 1, 2 and 3 indicates that these are not substantially altered with the inclusion of the money stock definitions after deleting lagged long rates. Finally, the lagged one-period interest rate appears to be statistically significant in equations 1,4 and 5 in Tables 2 and 3 , highlighting the strong correlation among the lagged pairs $\left(D R_{1, t}, D R_{3, t}\right)$ and $\left(D R_{1, t}, D R_{6, t}\right)$. Seasonality effects appear to have been well accounted for by the seasonal adjustments procedure since the 12th autocorrelation coefficient is insignificant in all cases. ${ }^{9}$

Interpretation of the coefficients of the systems is difficult since no structural model has been specified to anticipate, in prin-

\footnotetext{
${ }^{8}$ The Q-Portmanteau statistic is distributed as a chi-square with 9 degrees of freedom. The critical values for 0.05 and 0.01 significance levels are 16.9 and 21.7 respectively.

${ }^{8}$ Notice, however, that the Q-statistic seems to indicate possible misspecification in the equation for M2.
} 
ciple, their size or their sign. Notwithstanding, interesting observations can be made by applying some of the simple restrictions arising from theory.

First, if the expectation theory is correct, the impact of changes in the one month interest rate should be smaller the longer the maturity, since the long rate averages out changes stemming from the expected short rates. Therefore, the unrestricted coefficients on the lagged short interest rates should tend to decrease as maturity is increased. This appears to be the case for equations 3 and 6 in Table 1 and less so for equations 4 and 5 in Tables 2 and 3 .

This is a crucial point in the testing of the restrictions, since the forecasting coefficients implied by the expectations hypothesis would display smaller values the longer the maturity and such a result would support the theory. ${ }^{10}$ This is, in essence, the argument sustained by Modigliani and Shiller (1973).

One additional aspect, though not formally tested, concerns the relationship among the variances of the interest rate for the different maturities. Since long rates are averages of expected short rates, the variance of the former should be smaller than that of the actual short rates according to the expectation theory as shown by

\footnotetext{
${ }^{10}$ The forecasting coefficients that would results from the expectation hypothesis alone are $(1 / n) * e_{1}\left(A+A^{2}+\cdots+A^{n}\right)=(0.1817,0.004,-0.003)$ for the system $\left(D R_{1, t}, D P_{t}, D M_{1, t}\right)$. Compared to the unrestricted coefficients stemming from the equation for $D R_{3} t=(0.21082,0.01214,-0.1057)$ these would appear to be similar in pattems of signs and size, i.e., a larger coefficient for the changes in the inflation rate and the money growth rate. The table below shows the forecasting coefficients corresponding to the expectation hypothesis for the models shown in Tables 2 and 3.
} 
Shiller (1978) and LeRoy and Porter (1981) ${ }^{11}$. The coefficients of variation (CV) for $R_{1 t}, R_{3 t}$ and $R_{6 t}$ seem to be in agreement with the theory, since $\mathrm{CVa}\left(R_{1 t}\right)>C V\left(R T_{3 t}\right)>C V\left(R_{6 t}\right) .{ }^{12}$

Likewise, the one-period nominal interest rate displays a smaller variance than the actual inflation rate, which is also true for their first differences. A plausible explanation is that the nominal rate of interest, Fama (1975), can be looked upon as a predictor of the inflation rate and should consequently display a smaller

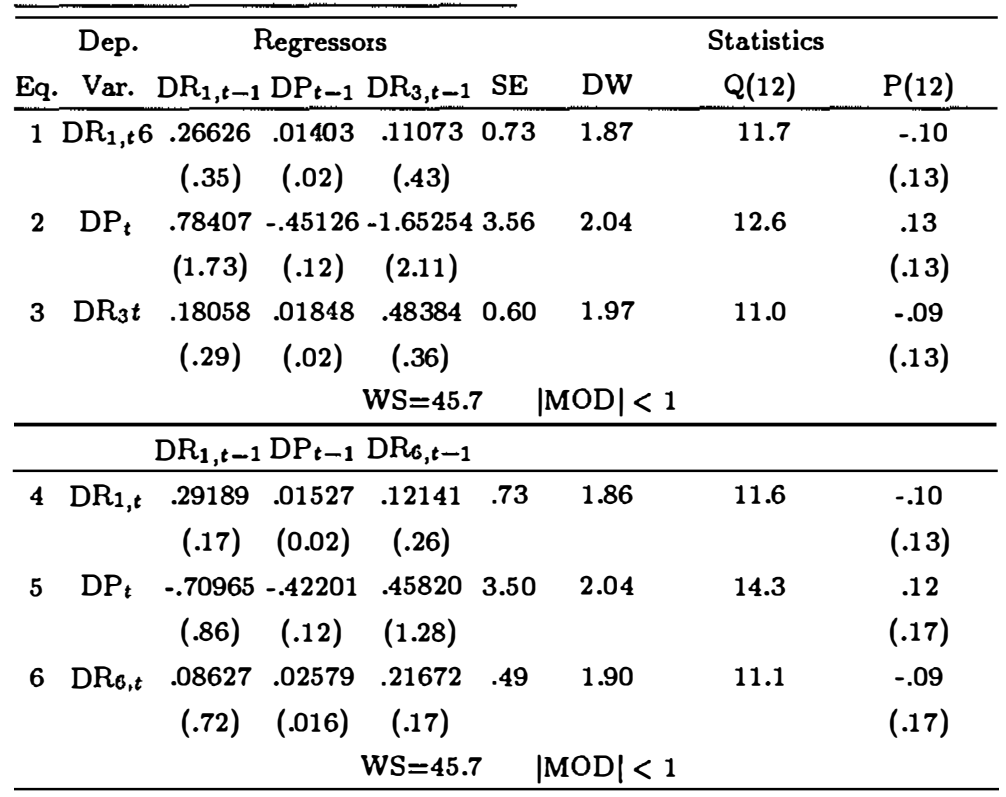

Notes: Sample period June 1977-June 1982. Monthly data; Standard errors are in parentheses below the estimated coefficients; SE: standard error of the regression; DW: Durbin-Watson statistic; $Q(12)$ : Q-Portmanteau statistic; $P(12)$ : twelfth autocorrelation coefficient of the residual from each equation. WS: Wald statistic for testing the significance of all coefficients of the system. $|\mathrm{MOD}|<1$ : indicates that the moduli of the eigenvalues of the system are less than one in absolute value.

Source: Tables 2 and 3.

${ }^{11}$ The formal test under this approach is not complete, in the sense that the permissible bounds will depend on the parameters of the forecasting system. See LaRoy and Porter (1980).

${ }^{12}$ The table below shows the summary statistics for computing the coefficients of variation for the period June 1977-June 1982. 
variance than the variable it is trying to predict. This, however, is only one of the properties that one would ask from a predictor; the other requirement is unbiasedness.

\subsection{Tests of the restrictions.}

The restrictions arising from theory are reproduced below for convenience:

(i) $e_{3} * A=(1 / n) * e_{1} *\left(A+\cdots+A^{n}\right)$

(ii) $e_{3} * A=(1 / n) * e_{2} *\left(A^{2}+\cdots+A^{n+1}\right)$

(iii) $e_{1} * A=e_{2} * A^{2}$

Table 4 shows the Wald tests, the computation of which needs only the estimation of the unrestricted systems $D R_{1, t}, D P_{t}, D R_{i t}$ ), $i=3,6$ shown in Table 1 . Table 5 shows the Wald tests for the systems shown in Tables 2 and 3.

Since all the systems estimated have an AR (1) representation and the restrictions apply to one of the rows of the $3 \times 3$ matrix $A$, the Wald test is asymptotically distributed as a chi-square with 3 degrees of freedom under the null hypothesis.

\begin{tabular}{|c|c|c|c|c|c|c|c|c|}
\hline \multirow[b]{2}{*}{ Eq. } & Dep. & \multicolumn{3}{|c|}{ Regressors } & \multirow[b]{2}{*}{ SE } & \multicolumn{3}{|c|}{ Statistics } \\
\hline & Var. & $\mathrm{DR}_{1, t-1}$ & $\mathrm{DP}_{\mathrm{t}-1}$ & $\mathrm{DR}_{3, t-1}$ & & DW & $Q(12)$ & $P(12)$ \\
\hline \multirow[t]{2}{*}{1} & $D R_{1, T}$ & .37025 & .01214 & .01013 & 0.75 & 1.85 & 12.9 & -.12 \\
\hline & & $(.13)$ & $(.02)$ & $(.01)$ & & & & (.13) \\
\hline \multirow[t]{2}{*}{2} & $D P_{\mathrm{t}}$ & .44475 & -.43287 & -.02172 & 3.67 & 2.03 & 14.0 & .13 \\
\hline & & $(.63)$ & $(.12)$ & $(.07)$ & & & & (.13) \\
\hline \multirow[t]{3}{*}{3} & $D M_{1} t$ & .38575 & -.20168 & .49632 & 5.85 & 2.21 & 10.8 & -.04 \\
\hline & & $(1.00)$ & $(.19)$ & $(.11)$ & & & & (.13) \\
\hline & & & & $W S=51.7$ & & $|\mathrm{MOD}|<1$ & & \\
\hline \multirow[t]{2}{*}{4} & $D R_{3} t$ & .21082 & .01214 & .01057 & .62 & 1.85 & 12.1 & -.13 \\
\hline & & $(.10)$ & $(.020)$ & $(.01)$ & & & & (.13) \\
\hline \multirow[t]{2}{*}{5} & $D R_{6} t$ & .20408 & .02088 & .00625 & .50 & 1.74 & 11.4 & -.09 \\
\hline & & $(.08)$ & $(.01)$ & $(.01)$ & & & & (.13) \\
\hline
\end{tabular}

Notes: Idem Table $1 . \mathrm{DM}_{1, t}$ was computed from the seasonally adjusted $\mathrm{M} 1$ definition of the money stock.

Notes: The mean and the standard deviation are expressed as a monthly percent.

Source: Own calculations. 
The following comments summarize a close examination of the results. 1) In all cases, the hypothesis are accepted at conventional significance levels, except for restriction (I) corresponding to the system $\left(D R_{1, t}, D P_{t}, D R_{3, t}\right)$

about the inflation rate are incorporated in the form indicated by the Fisher hypothesis, restriction (II) is accepted in all cases; thus the role of expectations in the determination and movements of the short and long rates is highlighted. 2) The definition of money stock used does not significantly affect the conclusions; for both, $M 1_{t}$ and $M 2_{t}$ the value of the Wald test increases for the six-month maturity, though it is not possible to assert from these facts that the hypothesis would be rejected if longer maturities were available. This is illustrated in Table 5 for the systems estimated in Table 2 and 3.

\section{Conclusions.}

The objective of this study has been the assessment of the role that inflationary expectations have played within the expectations hypothesis of the term structure. In doing so, a forecasting model was formulated and the restrictions arising from the Fisher and the expectations hypothesis were tested.

Though it is difficult to provide for an interpretation of the individual coefficients of the estimated unrestricted systems it has been possible to isolate some of the features that would accord with the predictions stemming from the theory: namely, that the forecasting coefficients show a declining pattern which is consistent with estimates of the unrestricted coefficients and secondly, the variances of the nominal rates are inversely related to the maturity of the financial asset.

When the restrictions (I-III) were formally tested by means of the Wald tests, these have supported, in most cases, their acceptance at conventional significance levels. Moreover, the tests seem to favor the acceptance of the restriction (II) even more strongly in spite of the stronger assumption being sustained. These results were not substantially altered when alternative definitions of the money stock were incorporated in the multivariate system.

The approach followed here has relied on the time behavior of interest rates of the various maturities by approximating the way in which expectations are formed by means of multivariate 
Table 1.

Estimation of Autoregressive Systems-A

\begin{tabular}{|c|c|c|c|c|c|c|c|c|}
\hline \multirow{2}{*}{ Eq. } & \multirow{2}{*}{$\begin{array}{l}\text { Dep. } \\
\text { Var. }\end{array}$} & \multicolumn{4}{|c|}{ Regressors } & \multicolumn{3}{|c|}{ Statistics } \\
\hline & & $\mathrm{DR}_{1, t-1}$ & $D P_{t-1}$ & $\mathrm{DR}_{3, t-1}$ & SE & DW & $Q(12)$ & $P(12)$ \\
\hline 1 & $\mathrm{DR}_{1, t} 6$ & $\begin{array}{c}.26626 \\
(.35)\end{array}$ & $\begin{array}{c}.01403 \\
(.02)\end{array}$ & $\begin{array}{c}.11073 \\
(.43)\end{array}$ & 0.73 & 1.87 & 11.7 & $\begin{array}{l}-.10 \\
(.13)\end{array}$ \\
\hline 2 & $\mathrm{DP}_{t}$ & $\begin{array}{l}.78407 \\
(1.73)\end{array}$ & $\begin{array}{c}-.4512 f \\
(.12)\end{array}$ & $\begin{array}{c}-1.65254 \\
(2.11)\end{array}$ & 3.56 & 2.04 & 12.6 & $\begin{array}{c}.13 \\
(.13)\end{array}$ \\
\hline \multirow[t]{3}{*}{3} & $\mathrm{DR}_{3} t$ & $\begin{array}{c}.18058 \\
(.29)\end{array}$ & $\begin{array}{c}.01848 \\
(.02)\end{array}$ & $\begin{array}{c}.48384 \\
(.36)\end{array}$ & 0.60 & 1.97 & 11.0 & $\begin{array}{l}-.09 \\
(.13)\end{array}$ \\
\hline & & & & $W S=45.7$ & & MOD $\mid<1$ & & \\
\hline & & $\mathrm{DR}_{1, t-1}$ & $D P_{t-1}$ & $\mathrm{DR}_{\varepsilon, t-1}$ & & & & \\
\hline 4 & $\mathrm{DR}_{1, t}$ & $\begin{array}{c}.29189 \\
(.17)\end{array}$ & $\begin{array}{l}.01527 \\
(0.02)\end{array}$ & $\begin{array}{c}.12141 \\
(.26)\end{array}$ & .73 & 1.86 & 11.6 & $\begin{array}{l}-.10 \\
(.13)\end{array}$ \\
\hline 5 & $\mathrm{DP}_{\mathrm{t}}$ & $\begin{array}{c}-.70965 \\
(.86)\end{array}$ & $\begin{array}{c}-.42201 \\
(.12)\end{array}$ & $\begin{array}{l}.45820 \\
(1.28)\end{array}$ & 3.50 & 2.04 & 14.3 & $\begin{array}{c}.12 \\
(.17)\end{array}$ \\
\hline \multirow[t]{2}{*}{6} & $\mathrm{DR}_{6, t}$ & $\begin{array}{c}.08627 \\
(.72)\end{array}$ & $\begin{array}{c}.02579 \\
(.016)\end{array}$ & $\begin{array}{c}.21672 \\
(.17)\end{array}$ & .49 & 1.90 & 11.1 & $\begin{array}{l}-.09 \\
(.17)\end{array}$ \\
\hline & & & & $W S=45.7$ & & $M O D \mid<1$ & & \\
\hline
\end{tabular}

Notes: Sample period June 1977-June 1982. Monthly data; Standard errors are in parentheses below the estimated coefficients; SE: standard error of the regression; DW: Durbin-Watson statistic; $Q(12)$ : Q-Portmanteau statistic; $P(12)$ : twelfth autocorrelation coefficient of the residual from each equation. WS: Wald statistic for testing the significance of all coefficients of the system. $|\mathrm{MOD}|<1$ : indicates that the moduli of the eigenvalues of the system are less than one in absolute value.

time series techniques. Similar results utilizing statistical methods such as those discussed by Shiller (1982), Leroy and Porter (1981) are not guaranteed. In order to complement the present analysis, further avenues of research may include aspects which relate to the implementation of the monetary policy and the operating characteristics of the financial institutions. Secondly, the high and variable inflation rate observed during the period may be indicative that the issue of uncertainty about the expected inflation rate be analyzed Hartman and Makin (1982), Kochin (1980), 
Table 2.

Estimation of Autoregressive Systems-B

\begin{tabular}{|c|c|c|c|c|c|c|c|c|}
\hline \multirow{2}{*}{ Eq. } & \multirow{2}{*}{$\begin{array}{l}\text { Dep. } \\
\text { Var. }\end{array}$} & \multicolumn{4}{|c|}{ Regressors } & \multicolumn{3}{|c|}{ Statistics } \\
\hline & & $\mathrm{DR}_{1, t-1}$ & ${ }_{1} \mathrm{DP}_{t-1}$ & $\mathrm{DR}_{3, t-1}$ & $\mathrm{SE}$ & DW & $Q(12)$ & $P(12)$ \\
\hline \multirow[t]{2}{*}{1} & $D R_{1, T}$ & .37025 & .01214 & .01013 & 0.75 & 1.85 & 12.9 & -.12 \\
\hline & & (.13) & $(.02)$ & $(.01)$ & & & & (.13) \\
\hline \multirow[t]{2}{*}{2} & $D P_{t}$ & .44475 & -.43287 & -.02172 & 3.67 & 2.03 & 14.0 & .13 \\
\hline & & (.63) & $(.12)$ & $(.07)$ & & & & (.13) \\
\hline \multirow[t]{3}{*}{3} & $D M_{1} t$ & .38575 & -.20168 & .49632 & 5.85 & 2.21 & 10.8 & -.04 \\
\hline & & $(1.00)$ & $(.19)$ & $(.11)$ & & & & $(.13)$ \\
\hline & & & & $\mathrm{WS}=51$ & & MOD $\mid<1$ & & \\
\hline \multirow[t]{2}{*}{4} & $D R_{3} t$ & .21082 & .01214 & .01057 & .62 & 1.85 & 12.1 & -.13 \\
\hline & & $(.10)$ & $(.020)$ & $(.01)$ & & & & (.13) \\
\hline \multirow[t]{2}{*}{5} & $D R_{6} t$ & .20408 & .02088 & .00625 & .50 & 1.74 & 11.4 & -.09 \\
\hline & & $(.08)$ & $(.01)$ & $(.01)$ & & & & (.13) \\
\hline
\end{tabular}

Notes: Idem Table 1. DM1,t was computed from the seasonally adjusted M1 definition of the money stock.

since the Fisherian relationship is altered with consequent effects on the term structure of interest rates.

\section{Appendix A: Analytical Derivatives of the Constraints}

The calculation of the derivatives of the restrictions required some minor modifications of a procedure presented by Baillie (1983).

For a trivariate system of the form (3.4) and unit vectors $e_{1}, e_{2}, e_{3}$, of size $3 m$, where $m$ is the number of lags. It can be shown that for a functional form of the type: $h(\Pi)=e_{1} * A^{k}$ where $\cap$ is the set of all elements of $A$

$$
D_{k}^{*} \equiv \frac{\partial h}{\partial \cap}=\left[\begin{array}{ccccccc}
\sum_{j=0}^{k-1} & \left(e_{1}\right. & * * A^{i j} & * & \left.e_{1}^{\prime}\right) & * & A^{k-1-j} \\
\sum_{j=0}^{k=1} & \left(e_{2}\right. & * & A^{i j} & \left.e_{1}^{\prime}\right) & * & A^{k-1-j} \\
\sum_{j=0}^{k-1} & \left(e_{3}\right. & * & A^{i j} & \left.e_{1}^{\prime}\right) & * & A^{k-1-j}
\end{array}\right]
$$

The relationship between $\partial\left(e_{1} * A^{k}\right) / \partial \cap=D_{k}^{*}$ and $\partial\left(e_{1} *\right.$ $\left.A^{k-1}\right) / \partial \cap=D_{k-1}^{*}$ can be shown to be of the form. 
Table 3.

Estimation of Autoregressive Systems-C

\begin{tabular}{|c|c|c|c|c|c|c|c|c|}
\hline \multirow{2}{*}{\multicolumn{2}{|c|}{$\begin{array}{l}\text { Dep. } \\
\text { Eq. Var. }\end{array}$}} & \multicolumn{4}{|c|}{ Regressors } & \multicolumn{3}{|c|}{ Statistics } \\
\hline & & $\mathrm{DR}_{1, t-1}$ & $D_{t-1}$ & $\mathrm{DR}_{2, t-1}$ & $\mathrm{SE}$ & DW & $Q(12)$ & $P(12)$ \\
\hline \multirow[t]{2}{*}{1} & $D R_{1, t}$ & .37114 & .00821 & -.05957 & 0.74 & 1.97 & 12.9 & -.12 \\
\hline & & $(.12)$ & $(.02)$ & $(.05)$ & & & & (.13) \\
\hline \multirow[t]{2}{*}{2} & $D P_{t}$ & -.43327 & -.4435 & -.15650 & 3.6 & 2.05 & 11.8 & .12 \\
\hline & & $(.61)$ & $(.12)$ & $(.23)$ & & & & (.13) \\
\hline \multirow[t]{3}{*}{3} & $D M_{2, t}$ & 1.2720 & -.01709 & .36548 & 1.76 & 1.82 & 21.3 & -.03 \\
\hline & & $(.29)$ & $(.06)$ & $(.12)$ & & & & $(.13)$ \\
\hline & & & & $\mathrm{WS}=56.6$ & & MOD $\mid<1$ & & \\
\hline \multirow[t]{2}{*}{4} & $\mathrm{DR}_{3, t}$ & .20650 & .00923 & .04638 & .62 & 1.94 & 13.2 & -.14 \\
\hline & & $(.10)$ & $(.02)$ & $(.04)$ & & & & $(.13)$ \\
\hline \multirow[t]{2}{*}{5} & $\mathrm{DR}_{6, t}$ & .20948 & .01735 & -.05141 & .50 & 1.82 & 11.0 & -.09 \\
\hline & & $(.08)$ & $(.01)$ & $(.03)$ & & & & (.13) \\
\hline
\end{tabular}

Notes: Idem Table $1 . \mathrm{DM}_{2, t}$ was computed from the seasonally adjusted M2 definition of the money stock.

Table 4.

Test of the restrictions-A

Wald Tests

\begin{tabular}{cccc}
\hline Rest. & (I) & (II) & (III) \\
\hline $\begin{array}{c}\text { Syst. } \\
\left\{\mathrm{DR}_{1}, \mathrm{DWP},\right.\end{array}$ & 13.04 & 3.37 & 3.17 \\
$\left.\mathrm{DR}_{3}\right\}$ & & & \\
$\left\{\mathrm{DR}_{1}, \mathrm{DP}\right.$, & & 6.23 & 6.01 \\
$\left.\mathrm{DR}_{6}\right\}$ & $7.89^{*}$ & & \\
\hline
\end{tabular}

Notes: The critical values from a chi-square distribution with three degrees of freedom are 7.81 and 11.3 at 0.05 and 0.01 significance levels respectively; $(0),(*)$ indicate that the null hypothesis could not be rejected at 0.05 and 0.01 significance levels respectively.

Source: Table 1. 


\section{Table 5.}

Test of the restrictions-B

Wald Tests

\begin{tabular}{cccc}
\hline Rest. & (I) & (II) & (III) \\
\hline Syst. & & & \\
$\mathrm{DR}_{1}, \mathrm{DP}, \mathrm{DM}_{1} \Rightarrow \mathrm{DR}_{3}$ & $1.65^{(0)}$ & $3.93^{(0)}$ & \\
& & & $6.19^{(0)}$ \\
$\mathrm{DR}_{1}, \mathrm{DP}, \mathrm{DM}_{1} \Rightarrow \mathrm{DR}_{6}$ & $5.28^{(0)}$ & $4.88^{(0)}$ & \\
$\mathrm{DR}_{1}, \mathrm{DP}, \mathrm{DM}_{1} \Rightarrow \mathrm{DR}_{3}$ & $1.94^{(0)}$ & $4.16^{(0)}$ & \\
& & & $5.35^{(0)}$ \\
$\mathrm{DR}_{1}, \mathrm{DP}, \mathrm{DM}_{2} \Rightarrow \mathrm{DR}_{6}$ & $7.95^{(*)}$ & $7.03^{(0)}$ & \\
\hline
\end{tabular}

Notes: Same as Table 4.

Source: Tables 2 and 3.

$$
\begin{gathered}
D_{k}^{*}=D_{k-1}^{*} A+\left[\begin{array}{lllllll}
e_{1} & * & A^{\prime k-1} & * & e_{1}^{\prime} & * & I \\
e_{2} & * & A^{\prime k-1} & * & e^{\prime} & * & I \\
e_{3} & * & A^{\prime k-1} & * & e_{1}^{\prime} & * & I
\end{array}\right] \\
\text { for } k=2,3, \cdots D_{1}^{*}=\left[\begin{array}{l}
I \\
0 \\
0
\end{array}\right]
\end{gathered}
$$

For instance, the size of $D_{k}^{*}$ will be $9 \times 3$ if $A$ is a $3 \times 3$ matrix, and $I$, and 0 are the $3 \times 3$ identity and null matrices respectvely. Using the results shown above, the Matrix $D$ that appears in the Wald Statistics for the restriction $g_{1}(\cap)=(1 / n) * e_{1} *(A+\cdots+$ $\left.A^{n}\right)-e_{3} * A$

$$
D=\partial g(\cap) / \partial \cap \equiv\left(D_{1}^{*}+\cdots+D_{n}^{*}\right) *(1 / n)-\left[\begin{array}{l}
0 \\
0 \\
I
\end{array}\right]
$$

Similar calculations can be performed for the constraints implied by the Fisher Hypothesis.

\section{References}

Baillie, R., R. Lippens and P. McMahon. Testing Rational Expectations and Efficiency in the Foreign Exchange Market. Econometrica, 51:553-563, 1983. 
Banco Central de la Republica Argentina. Boletin Estadistico. Buenos Aires, Several issues.

Box, G. and G. Jenkins. Time Series Analysis and Control. San Francisco, Holden Day, 1976.

Engle, R Wald. Likelihood Ratio and Lagrange Multiplier Tests in Econometrics. Discussion Paper 81-20. Department of Economics, Univ. of California, San Diego.

Fama, E. Short-Term Interest Rates as Predictors of Inflation. American Economic Review, 65:265-282, 1975.

Fisher, I. Theory of Interest. Reprints of Economic Classics New York, A.H. Kelley, 1967.

Fuller, W. Introduction to Time Series Analysis. New York, John Wiley and Sons, 1976.

Granger, C. and Newbold, P. Forecastıng Economic Time Series. New York, Academic Press, 1977.

Hartman, R. and Makin, J. Inflation Uncertainty and Interest Rates: Theory and Empirical Tests. Discussion Paper. Department of Economics, University of Washington.

Hakkio, C. The Term Structure of the Forward Premium. Journal of Monetary Economics, 9: 41-58, 1981.

Harvey, A. Time Series Model. New York, John Wiley and Sons, 1981.

Hoffman, D. and Schlagenhavj, D. Rational Expectations and Monetary Models of Exchange Rate Determination. Journal of Monetary Economics, 11:247-260, 1983.

Hoffman, D. and Schmidt, P. Testing the Restrictions Implied by the Rational Expectations Hypothesis. Journal of Econometrics, 15: 265-287, 1981.

Judge, et al. Wiley Series in Probability. The Theory and Practice of Econometrics. New York, John Wiley and Sons, Inc, 1980. Kochin, Levis. Interest Rates and Uncertain Future Price Levels: Irving Fisherś Money Illusion. Discussion Paper, Department of Economics, University of Washington,1980.

LeRoy, S. and Porter, R. The Present Value Relation: Tests Based on Implied Variance Bounds. Econometrica, 49:555-574, 1981.

Lucas, E. and Sargent, T. Rational Expectations and Econometric Practice. Minneapolis, University of Minnesota Press, 1981.

Modigliani, F. and Shiller, R. Inflation, Rational Expectations, and the Term Structure of Interest Rates. Economica, 40:12- 
43, 1973.

Muth, J.F. Rational Expectations and the Theory of Price Movements. Econometrica, 29: 315-335, 1961.

Nelson, C. The Term Structure of Interest Rates. New York, Basic Books, 1972.

Nelson, C. Rational Expectations and the Predictive Efficiency of Economic Models. The Journal of Business, 48:331-343, $1975 \mathrm{a}$.

Nelson, C. Rational Expectations and the Estimation of Econometric Models. International Economic Review, 1975b.

Nelson, C. and Schwert, W. On Testing the Hypothesis that the Real Rate of Interest is Constant. American Economic Review, 67:478-486, 1977.

Roll, Richard. The Behavior of Interest Rates: An Application of the Efficient Market Model to U.S. Treasury Bills. New York, Basic Books, 1970.

Sargent, Thomas. A Note on Maximum Likelihood Estimation of the Rational Expectations Model of the Term Structure. Journal of Monetary Economics, 5: 133-143, 1979.

Shiller, Robert, J. The Volatility of Long Term Interest Rates and Expectations Models of the Term Structure. Journal of Political Economy, 87:1190-1219, 1978.

Tiao, G. and Box, P. Modeling Multiple Time Series. Journal of the American Statistical Association, 76: 802-916, 1980.

Wallis, K. Econometric Implications of the Rational Expectations Hypothesis. Econometrica, 48: 1481-1497, 1980. 
